\title{
The Application of Foreign Language Teaching Method in Korean Education
}

\author{
Shuaihua Song \\ The Korean Department College of International Cooperation Xi'an International University Xi'an \\ Shaanxi China, 710048
}

Keywords: Foreign language teaching method, Korean education, Application.

\begin{abstract}
Foreign language teaching method is a effective method for foreign language learning, through the comprehensive application of the teaching method of theory and the elements of language learning and flexible application system, realize students' foreign language learning with the combination of theory and practice of learning mode, promote students to grasp a foreign language. Many students of foreign language major is Korean learning, through exploring application of foreign language teaching in Korean language education, Korean language learning theory, analysis of Korean teaching effective teaching, pay attention to Korean vocabulary teaching and grammar teaching, for speaking and writing of Korean language education and improve students' comprehensive practical ability in Korean such as Korean education, to promote the comprehensive promotion of Korean teaching level.
\end{abstract}

\section{Introduction}

The application of foreign language teaching should first clear the characteristics and rules of foreign language curriculum, and according to its characteristics and rules, and students' learning foundation and ability to accept the situation in a reasonable teaching task set, clear teaching objectives and requirements, and the teaching activities are arranged reasonably, arrange the teaching content, at the same time teachers the need to strengthen their professional teaching ability, and guide students to master the appropriate teaching methods, so as to promote students' learning efficiency, achieve the desired teaching goal, the teaching method has obvious advantages in foreign language teaching, widely praised by teachers and students. At the same time, with the influence of Korean culture, social concern for South Korea and Korean gradually increase, many students are learning Korean professional, or will it as a second language study, Korean and Chinese have similar social and cultural background, but its shape and application pattern and the Chinese difference teaching method applied in foreign language teaching in Korean can effectively enhance the comprehensive learning and application level of students, and promote the realization of teaching goal[1].

\section{Korean language learning theory and language and culture background}

The need for Korean teaching the first comprehensive cognition of the Korean language and Korean language theory, to fully understand the cultural background, the contents of these studies contribute to the expression for more in-depth grasp. Korean international official language of the Republic of Korea, mainly refer to proverbs text as its linguistic markers, early Korean folk influenced by Han culture, and more will use Chinese characters as its text marker, without voice tag system independent, until fifteenth Century hunminjeongum was the invention and application, but it has not been applied fully until twentieth Century, hunminjeongum was widely carried out in the Korean Peninsula range, and gradually formed a relatively complete system of language. Hunminjeongum is mainly composed of letters and phonemes mark, modern hunminjeongum is mainly composed of twenty-four letters, vowels have ten consonants, fourteen vowels, the creation principle influenced by traditional culture Chinese, produced by the principle made, a spell, 
relatively simple way, this is the main reason of Korean spread in a short period of time, there are everyday words and expressions in the honorific usage, application of everyday language is more casual, and communication on important occasions and objects for the elderly, the language is not familiar with the need to pay more attention to the application of honorifics, language communication object subjective feelings, language learning is not only to master the language, students need to master the correct way of application, in order to achieve the accurate and flexible Application. Teachers in foreign language teaching, to enable students to master the form and style of Korean characters, Korean vocabulary pronunciation habits and spelling, to correctly grasp the syntactic structure of Korean sentences, and a variety of Korean syntactic elements of a deep understanding of nature of learning the target language is to achieve a flexible application and interpersonal communication the language through language learning, so that students in language control ability and application ability, also is the key problem of teachers need to pay attention to in the teaching process[2].

\section{Korean teaching effective teaching organization}

The teaching organization includes many aspects, to carry out the teaching mode, teaching object, teaching scale, teaching content, teaching activities are a teaching organization, teaching the need for Korean teachers to carry out teaching activities of the organization effectively, we should make clear the object of teaching and teaching methods, different groups of students in the learning foundation and the ability to accept there will be a big difference, the teaching object clearly helps to set the teaching goal and the teaching plan, reasonable arrangement of teaching content and teaching plan in classroom teaching schedule, teaching methods according to different application of teaching contents, language learning is relatively boring, effective teaching methods to enhance students' interest in learning and the initiative, to enable students to actively cooperate with relevant teaching activities of teachers, enhance the Students' learning efficiency and learning quality, so as to achieve the desired effect of classroom teaching[3].

\section{Korean vocabulary teaching and grammar teaching}

Vocabulary learning is the basis for learning any language, learning Korean also need to have a lot of Korean vocabulary can achieve flexible application, so the teachers should guide the students to pay attention to in the teaching activities of Korean vocabulary learning, vocabulary learning is that students achieve basic writing abilities, and vocabulary teaching is the core of foreign language teaching the method, how to let the students to high solid memory Korean vocabulary is a comprehensive subject must consider teachers. Korean vocabulary can be divided into Chinese characters, words inherent words and foreignwords, because Chinese is the basis of Korean word formation, thus Chinese characters holds an enormous proportion in the Korean vocabulary system, Korean vocabulary has nearly $70 \%$ words are Chinese characters, along with the development of modern society, the communication between countries and the increasingly frequent exchanges of foreign words as an important component of the Korean vocabulary system, but Chinese characters words and foreign words from the Korean pronunciation form[4].

Korean vocabulary has strong regularity, therefore teachers' vocabulary teaching can carry out teaching activities according to the law application of Korean, according to the practical experience in teaching, effective teaching methods for Korean vocabulary teaching includes the following aspects: first, explain the meaning and application of Chinese Korean words for comparison of vocabulary learning, have a high frequency of use many words in daily study life, teachers can these words and Korean antithesis learning, such as mother, father, Hello, the association between students through the two party will be able to quickly grasp the Korean vocabulary; secondly, Korean language vocabulary teaching method based on word formation of Korean vocabulary, consisting of different forms of elements, is the simple words a separate form element, and the compound is composed of many forms of elements, the teachers can direct words The meaning of direct vocabulary instruction for students, for the learning of compound words is required according 
to the composition teaching mode and application mode, need to grasp the root suffix or prefix, grasp the word formation of Korean vocabulary can effectively improve students' learning efficiency; thirdly, to vocabulary teaching according to the application characteristics of vocabulary, Korean vocabulary and there will be a similar Chinese vocabulary, synonyms or antonyms, teachers will be able to carry out vocabulary teaching activities according to the application characteristics, application of similar meaning in the opposite way, improve students' memory efficiency, so as to realize the expansion of vocabulary[5].

An important part of grammar study is language learning, many teachers are weakening grammar education phenomenon in Korean language teaching, grammar is the language summary of the application law, can realize the flexible application of Korean grammar grammar learning can be learned without teacher, but the students will form the Korean vocabulary has the application value of the sentence, grammar teaching is an important foundation for autonomous learning assisted students, teachers of Korean grammar teaching need to uphold the four main principles: first, attention to the correlation between context, grammar of Yu Wen Zhang Zhizhong, its application also requires attention to the correlation between the application context, the meaning of the article content for teaching to enhance students' understanding; second, the importance of using grammar the grammar teaching is that students were expected to use Korean grammar sentence The organization and decomposition, so as to realize the flexible application of Korean vocabulary and sentence patterns in different language environment, and teachers in the daily teaching activities will need to pay attention to grammar practice, promote the students' application level; third, pay attention to the principles of economy, teachers of Korean grammar teaching need to master the appropriate scale, pay attention to the principle of economy, not only pay attention to grammar teaching and should not spend too much time in teaching; fourth, adhere to the principle of relevance of grammar, grammar teaching teachers can not be used blindly teaching mode, need to be used in a reasonable grammar language environment to explain the importance relation between grammar and linguistic environment then, to promote students to understand teaching content[6].

\section{For listening, speaking, reading and writing skills Korean Education}

I heard master the ability to read and write is a key measure of students' language level, so the teachers to carry out teaching activities can also set different teaching contents according to the different aspects of the application, the ability of training.

Listening is an important part of language learning, but also an important part of learning Korean teaching, modern education will introduce various teaching techniques to classroom teaching, teachers can use multimedia teaching methods for students to play with the broad social impact of Korean film and television works, they are applied to the Korean culture, pay attention to the interest, to carry out the Korean listening activities. Korean TV drama works in the application and pronunciation are relatively pure, is the ideal of listening materials, students in the language environment influence themselves, enhance its ability for Korean defense knowledge and comprehension ability, and gradually improve their listening ability in korean. A short time many teachers in the listening training audio will choose in the initial period of classroom teaching, the students of this period has not yet fully focused attention, the teaching result is not ideal, teachers can choose suitable practice to adjust teaching content, improve the efficiency of classroom teaching to promote.

Proficient in Korean and other languages is the main goal of language learning, and Korean language skills but also the teachers need to strengthen the key links, teachers should encourage students to actively speak Korean, constantly in the application to enhance the application level of korean. For example: the teacher can regularly carry out "learning Korean corner", "Korean exchange hour" teaching activities, to enable students to communicate with each other, will enhance the grammar of Korean vocabulary, Korean master knowledge for flexible application, enhance their application of Korean self-confidence, dare to use Korean Autonomous expression of thoughts and ideas, enhance the language the expression ability in the process. Teachers can guide the students in daily life, and the students also actively applied Korean exchanges, covered many 
Korean applications, continue to strengthen the students' oral English training consciousness, and enhance the quality of oral English teaching.

Reading teaching is also a key part of language teaching. Korean reading teaching can expand students' vocabulary, promote students' listening and speaking level and writing and translation level, and promote students' overall language learning ability. Teachers need to pay attention to the cultivation of students' ability of discourse analysis in teaching activities, has established the level and structure of the article, students discourse analysis ability can make the students for the structure, meaning, meaning there are more in-depth understanding, and guide students to master reading slightly and precision of reading skills, promote improving the reading ability of students.

The key problem of writing teaching is teachers' concern, writing training for students is the basis for language and language translation, the teachers can use self introduction writing, document writing and other topics writing and strengthen students' writing level in daily teaching activities, to enable students to have the application value of the modern society master writing way then, to promote students' ability of Applied Korean development practice.

\section{To enhance students' comprehensive application skills in Korean}

The nature of purpose is to achieve learning Korean Korean Korean language teachers for flexible application, comprehensive application of practical training, the need for different levels of strengthening practical ability according to different learning basis. For example: the comprehensive application of the teachers can use cooperative learning mode and task-based teaching method, the students will be divided into different study groups, organize the students to carry out the Korean folk culture of learning activities, students are required to understand the mode of team based learning Korean folk, students will obtain the learning content about Korean folk culture, through independent cyber source library resources so, the different students ability to achieve as it can, and learning content group to learn the form of a report to teacher feedback, through the teaching activities to enable students to hear the ability of reading and writing has been applied comprehensive, objectively summarize the teacher according to the students' learning situation, comprehensive evaluation for the students' learning attitude, learning methods and learning results are correct, the students in the learning process. And to conduct correct study methods to guide students so as to improve their practical ability. Through the completion of many similar learning tasks can effectively enhance the learning and application level of the students, and to enhance its understanding of Korean culture, and to cultivate the students to study Korean interest in learning, promote the subsequent teaching activities[7].

\section{Conclusion}

Korean teaching is the teaching process of the teachers in the teaching process through the Korean language theory and language cultural background teaching, effective teaching, teaching Korean Korean vocabulary teaching and grammar teaching, for speaking and writing of Korean language education and improve students' comprehensive practical ability in Korean and other measures, the formation of foreign language teaching a complete system, the application of foreign language teaching method to enhance the comprehensive learning ability of students, to promote the realization of teaching goal of Korean subjects.

\section{References}

[1]Barnes B D, Lock G. Student Perceptions of Effective Foreign Language Teachers: A Quantitative Investigation from a Korean University.[J]. Australian Journal of Teacher Education, 2013, 38(2):19.

[2]Seo H. A Study on the teaching methods of the Korean postposition $\lceil\mathrm{RO}\rfloor$ in Korean Language Education as a Foreign Language[J]. Bulletin of Niigata University of International \& Information Studies Department of Information Culture, 2005, 8:19-38. 
[3]Deng X Z. Application of ideas of CDIO in foreign language teaching - - Take Korean language teaching as the example[J]. Journal of Nanchang College of Education, 2012.

[4]Barnes B D, Lock G. Student Perceptions of Effective Foreign Language Teachers: A Quantitative Investigation from a Korean University.[J]. Australian Journal of Teacher Education, 2013, 38(2):19.

[5]Park J K, Mi K K. Teaching and Learning of EIL in Korean Culture and Context[J]. English Language Education, 2014, 1:47-61.

[6]Taeho C. A STUDY ON TEACHING METHOD OF KOREAN AS A SECOND LANGUAGE AND TEACHER TRAINING SYSTEM[J]. Cereal Foods World, 2009, null(82):465-482.

[7]Barnes B D, Lock G. Student Perceptions of Effective Foreign Language Teachers: A Quantitative Investigation from a Korean University.[J]. Australian Journal of Teacher Education, 2013, 38(2):19. 